Aletria, Belo Horizonte, v. 29, n. 4, p. 29-48, 2019

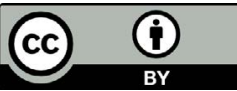

\title{
"Your Words and Your Performances Are no Kin Together": um estudo sobre o clown do teatro shakespeariano
}

\section{"Your Words and Your Performances Are no Kin Together": A Study on the Clown from Shakespeare's Drama}

Erika de Freitas Coachman

Universidade Federal do Rio de Janeiro (UFRJ), Rio de Janeiro, Rio de Janeiro / Brasil erikacoachman@hotmail.com

Resumo: Formado pela fusão de ator e personagem, o clown do palco shakespeariano não se submetia à tirania do script: sua atuação era marcada por improvisos e interações com o público. O presente artigo busca transcender a análise do texto dramático para lançar luz sobre ele, uma criatura do teatro elisabetano-jaimesco que desafiava e reinventava a peça concebida por seu criador. No espaço liminal entre palco e realidade, sua performance cômica roubava a cena, tornando a experiência teatral inescapavelmente imprevisível.

Palavras-chave: clown; roteiro; performance; Shakespeare.

Abstract: Formed by a blend of actor and character, the clown from the Shakespearean stage did not submit to the tyranny of the script: his performance was marked by improvisation and spontaneous interactions with the audience. This paper aims at transcending the boundaries of a textual analysis of the Bard's drama so as to shed light on the clown, a creature of the Elizabethan and Jacobean drama who challenged and reinvented the play as conceived by the dramatist. In this liminal space between stage and reality, the clown's performance stole the scene, turning the dramatic experience into an unpredictable event for playgoers.

Keywords: clown; script; performance; Shakespeare. 


\section{Introdução}

Analisar o riso provocado pelas performances cômicas shakespearianas faz parte de um esforço arqueológico, uma tentativa de reconstruir os significados transmitidos por essas representações à luz das crenças, valores e conhecimentos próprios do público da época elisabetana-jaimesca. Um dos principais obstáculos é o desafio imposto pela efemeridade das representações teatrais, repletas de improvisos, trejeitos, tons de voz e imprevistos que uma mera análise do texto dramático não é capaz de recuperar. Este artigo concentra seu foco no que há de mais efêmero, incontinente e imprevisível no teatro shakespeariano, a saber, as performances cômicas dos clowns.

Mas quem eram eles? Segundo Wiles, ${ }^{1}$ o termo clown é uma invenção da era elisabetana: a palavra foi criada para designar um rústico que, por conta de sua rudeza e ingenuidade, era visto como alguém inferior e ridículo. Eram os clowns as grandes celebridades da época, responsáveis por atrair as massas para o teatro. ${ }^{2}$ Quando dizemos hoje, metonimicamente, que estudamos Shakespeare, Marlowe ou Jonson, por exemplo, concentrando todo o estrelato nas figuras dos dramaturgos, estamos, na verdade, invertendo a percepção do público elisabetano:

Como todos sabemos, eram os dramaturgos que começavam no anonimato, suas identidades totalmente obscuras para a apreensão das plateias. [...] eram os comediantes, como Richard Tarlton e Will Kemp, que eram as primeiras celebridades do palco da modernidade nascente. ${ }^{3}$

\footnotetext{
${ }^{1}$ WILES. Shakespeare's Clown: Actor and Text in the Elizabethan Playhouse, p. 61. ${ }^{2}$ A proeminência do clown também ficava evidente na composição da companhia teatral Queen's Men. Dos doze acionistas da companhia, seis eram comediantes - a saber, Richard Tarlton, Robert Wilson, John Singer, John Adams, John Garland e John Laneham. O papel majoritário dos atores cômicos na administração da companhia, hoje contrasta com o tamanho aparentemente reduzido dos papéis que lhes cabiam nos textos dramáticos a que temos acesso (PREISS. Clowning and Authorship in Early Modern Theatre, p. 64).

3 "As we all know, it was dramatic authors who began as anonyms, their identity the most obscured from audiences' apprehensions. [...] it was the comedians, like Richard Tarlton and Will Kemp, who were the first celebrities of the early modern stage" (PREISS. Clowning and Authorship in Early Modern Theatre, p. 6, tradução minha).
} 
Quando vemos o texto dramático como outro texto literário qualquer, e descartamos da análise o efeito desestabilizador da performance, o clown - um dos principais responsáveis pelo improviso no palco elisabetano - parece ser empurrado para as margens e perder a importância e centralidade que tinha nos tempos de Shakespeare. Afinal, $\mathrm{o}$ ator cômico não seguia a ditadura de um script:

Apesar do clown em uma peça elisabetana ter um papel muito pequeno, ele podia fazer muito a partir dele, sempre havia a possibilidade de um jig ou de uma exibição parecida no final, o que mostraria sua habilidade com dança e acrobacias. O que parece ser um papel insignificante nas páginas de um livro poderia facilmente se expandir para uma contribuição animada e significativa no palco. ${ }^{4}$

O papel do clown não ficava limitado à história da peça encenada no palco, pois sua atuação também incluía em boa medida a função de controlar a participação da plateia e evitar que a desordem inviabilizasse o espetáculo. Quando a continuidade da apresentação estava sob ameaça, era hora do clown subir ao palco para acalmar os ânimos da multidão. ${ }^{5}$

\section{As origens do clown}

"Nothing that is so, is so" (Noite de Reis, 4.1.6-7)

Construir uma árvore genealógica para o clown do palco shakespeariano é uma tarefa complexa; afinal, Shakespeare lançou mão das mais diversas fontes de inspiração para compor sua obra, sem se manter fiel a esta ou àquela tradição. A diversificada ascendência dessa

\footnotetext{
4 "Though a clown in Elizabethan play has a very small written part he may well have made much of it, there was always the possibility for the jig or a similar exhibition at the end which would show the clown's dancing or tumbling ability to advantage. What looks like an insignificant part on the pages of a book could easily expand into a significant lively contribution on the boards" (VIDEBAEK. The Stage Clown in Shakespeare's Theatre, p. 2, tradução minha).

${ }^{5}$ PREISS. Clowning and Authorship in Early Modern Theatre, p. 64.
} 
grande figura cômica do teatro renascentista inglês é descrita de modo sucinto no panorama a seguir:

O clown do palco elisabetano é um conglomerado de um grande número de diferentes ancestrais, que contribuíram para a formação das suas características. Alguns desses diversos elementos pertencem a um passado distante, outros são ainda parte da cultura teatral, enquanto outros são contemporâneos do próprio clown. O criado cômico nas peças romanas e gregas, o Vício do teatro das moralidades [e dos interlúdios] e a tradição da comedia dell'arte contribuíram para a habilidade de réplica do clown e para sua tradição acrobática. A ideia do idiota do vilarejo e do cabeça dura do interior o presentearam com franqueza e ingenuidade, o que lhe servem bem na hora de dizer verdades a quem não gostaria de ouvi-las. Finalmente, o histórico bobo da corte acrescentou à parte do clown a liberdade para se expressar, o profissionalismo e as muitas peças da sua vestimenta. ${ }^{6}$

$\mathrm{Na}$ hora de construir um determinado clown, Shakespeare parecia selecionar traços, linguagens e trejeitos dentre as mais diferentes tradições, tendo em vista a natureza da função que ele desempenharia na trama e o efeito que desejava causar na plateia. Um dos ancestrais mais importantes do clown era o Vício ${ }^{7}$ - uma figura emblemática do teatro

6 "The Elizabethan stage clown is a conglomerate of a large number of different ancestors, all of whom have contributed to the formation of the clown's characteristics. Some of these diverse elements belong in quite a distant past, others are still part of the theatrical culture, while some are contemporaries of the clown's. The comic servant in Greek and Roman plays, the Vice of the medieval morality plays and the commedia dell'arte tradition contributed to the clown's skillful repartee and the tradition for his acrobatic tumbling. The idea of the village idiot and the country clod gave him his straightforwardness and naivete, which often serves him well when he delivers home truths to unwilling ears. Finally the historical court fool or jester added to the clowns part his free license of speech his professionalism and many articles of dress" (VIDEBAEK. The Stage Clown in Shakespeare's Theatre, p. 2, tradução minha).

${ }^{7}$ Segundo Wiles (Shakespeare's Clown: Actor and Text in the Elizabethan Playhouse, p. 4-5), o nome "Vício" era frequentemente empregado como sinônimo de "bobo" (em inglês, $f o o l$ ) no século XVI. O parentesco entre as duas figuras também seria evidente 
das moralidades e dos interlúdios ${ }^{8}$ - que desempenhava uma função central na peça, atuando como uma espécie de mestre de cerimônias à medida que controlava o jogo encenado no palco. ${ }^{9}$ Ao mesmo tempo, ele se situava em um espaço marcado pela liminalidade: em parte, ele era a personagem que representava no palco; ao mesmo tempo, não deixava de ser um ator cômico, cujos comentários e apartes direcionados diretamente à plateia insistiam em romper a ilusão cênica. ${ }^{10} \mathrm{O}$ clown se destaca das demais personagens por deliberadamente entrar e sair da trama, exibindo este ou aquele sentimento não apenas em resposta ao desenrolar da ação da peça, mas também para ter ocasião de exibir seu talento como solo performer. ${ }^{11}$

Diversas características separam o Vício e o clown elisabetano da trama em que aparecem; sua linguagem, por exemplo, não é rebuscada em geral, os porta-vozes do humor preferem a liberdade da prosa de um sujeito comum à rigidez de uma métrica rebuscada. ${ }^{12}$ Do mesmo modo, a obediência à sequência do roteiro pode ficar em segundo plano: os papéis do Vício e do clown caracterizam-se justamente por sua incontinência, pela desordem e pela espontaneidade do jig, ${ }^{13}$ dos improvisos e da morris dance. ${ }^{14}$

pelo modo como se vestiam: diversas referências da época indicam que o Vício usava, de fato, vestimentas semelhantes às do bobo.

${ }^{8}$ WILES. Shakespeare's Clown: Actor and Text in the Elizabethan Playhouse, p. xi.

${ }^{9}$ WILES. Shakespeare's Clown: Actor and Text in the Elizabethan Playhouse, p. 2.

${ }^{10}$ WILES. Shakespeare's Clown: Actor and Text in the Elizabethan Playhouse, p. 2.

${ }^{11}$ WILES. Shakespeare's Clown: Actor and Text in the Elizabethan Playhouse, p. 6. PREISS. Clowning and Authorship in Early Modern Theatre, p. 65.

${ }^{12}$ WILES. Shakespeare's Clown: Actor and Text in the Elizabethan Playhouse, p. 6.

${ }^{13}$ Nos tempos de Shakespeare, dava-se o nome de jig a uma canção cômica frequentemente obscena - acompanhada de uma dança vigorosa. Essa performance musical, popularizada pelo clown Richard Tarlton, frequentemente sucedia a apresentação da peça (DOBSON; WELLS. The Oxford Companion to Shakespeare, p. 224).

${ }^{14}$ Morris dance era uma dança folclórica característica dos festivais da era Tudor, comandada por um Lord of Misrule (WILES. Shakespeare's Clown: Actor and Text in the Elizabethan Playhouse, p. 31; VIDEBAEK. The Stage Clown in Shakespeare's Theatre, p. 4). Originalmente, ela tinha o objetivo de celebrar a escolha de um rei do verão ou de uma dama de maio; no apagar das luzes do século XVI, o ritual já havia sofrido mudanças e seu líder passou a ser um bobo, responsável por conduzir a dança. Durante a execução da morris dance, o bobo cortejava um homem disfarçado de mulher, que 
Tanto o Vício quanto o clown operam como "procedimentos extradramáticos" ${ }_{15}^{15}$ um composto híbrido de ator cômico e personagem cuja função é nos fazer lembrar a todo tempo que a peça nada mais é do que um jogo de performance. Também é sua tarefa convidar a plateia para participar desse jogo, sem se esquecer de controlar esse engajamento para assegurar a continuidade da peça. A possibilidade de improvisar fica evidente na imprecisão de comandos como "lutar" ou "cantar". ${ }^{16}$

É fácil detectar a influência do Vício na tessitura de vilões shakespearianos com senso de humor, como é o caso de Iago (Otelo) e Ricardo III ${ }^{17}$ cuja troca de confidências com a plateia por meio de apartes e solilóquios repletos de humor negro frequentemente fazem o espectador se sentir culpado ao rir deles e com eles. Mas também é preciso estar atento às diversas diferenças que distinguem o Vício do clown do palco shakespeariano. Como explicar a transformação do Vício, uma personagem astuta e perspicaz, na figura do rústico ingênuo e nada inteligente? Talvez a resposta possa ser encontrada nas condições sociais e históricas de seus respectivos teatros.$^{18} \mathrm{O}$ Vício das moralidades e dos interlúdios era uma criação do teatro promovido por companhias itinerantes; antes de 1594, não era preciso contar com um vasto repertório: "uma única peça podia atender vinte vilarejos". ${ }^{19}$ A figura do clown, por sua vez, é um produto da demografia e das condições de performance da Londres elisabetana. ${ }^{20}$ Quando, em 1576, James Burbage inaugurou o Theatre, sua intenção não era oferecer um lar permanente para uma companhia teatral específica; foram necessárias quase duas décadas para que, a partir de 1594, grupos teatrais abandonassem a tradição itinerante

representava uma versão burlesca da rainha de maio conhecida como a Donzela Marian (WILES. Shakespeare's Clown: Actor and Text in the Elizabethan Playhouse, p. 44). 15 "Extradramatic procedures" (PREISS. Clowning and Authorship in Early Modern Theatre, p. 66, tradução minha).

${ }^{16}$ PREISS. Clowning and Authorship in Early Modern Theatre, p. 66.

${ }^{17}$ PREISS. Clowning and Authorship in Early Modern Theatre, p. 65.

${ }^{18}$ PREISS. Clowning and Authorship in Early Modern Theatre, p. 66.

19 "One play could serve twenty towns" (GURR, apud KASTAN. Shakespeare's Playhouses, p. 80, tradução minha).

${ }^{20}$ PREISS. Clowning and Authorship in Early Modern Theatre, p. 66. 
para se fixar em um único lugar. ${ }^{21}$ É nesse contexto de sedentarismo recente que surgiu o teatro shakespeariano, cujo desafio mais premente era atender às vontades da plateia londrina, composta por um segmento crescente de imigrantes recém-chegados do campo - para quem a figura cômica do rústico ingênuo tinha um apelo irresistível. ${ }^{22}$

As festas populares e o folclore inglês também contribuíram sobremaneira para a construção do clown shakespeariano. Nos tempos do Bardo, não havia uma linha divisória nítida para demarcar os limites entre as tradições do teatro e o espírito festivo inglês, de modo que o Vício das moralidades e dos interlúdios e o clown do palco de Shakespeare guardavam grandes semelhanças com o Lord of Misrule das festas populares. Além disso, o clown exercia uma função importante enquanto oponente das massas: nas palavras de Preiss, ${ }^{23}$ o "Carnaval precisa de uma autoridade para antagonizar", e o clown também supria essa necessidade, colocando-se como um emissário da Quaresma, um rival da alegria das massas. Ele personificava o Jack-a-Lent, uma figura da cultura popular que, na Quaresma, tomava a forma de um boneco feito de palha contra o qual as crianças arremessavam pedras - um ritual de destruição acompanhado por uma multidão alegre e barulhenta. Anualmente, o pobre Jack-a-Lent era apedrejado, queimado ou até jogado do alto de chaminés; mas, para a diversão geral, ele sempre ressurgia no ano seguinte, quando era submetido a novos tormentos. ${ }^{24}$

Analisada sua ancestralidade, o clown do teatro shakespeariano surge como uma figura híbrida, um composto formado ao mesmo tempo pela oposição e pela resiliência do Jack-a-Lent, pelo discurso cômico e sedutor do Vício, pela ingenuidade do camponês inglês, pela liderança desordeira do Lord of Misrule e pela língua afiada do servo do teatro clássico. Mas a genialidade de Shakespeare não ficou limitada à arte de combinar fontes de inspiração tão diversas: uma de suas grandes inovações foi a fusão do clown e de seu ancestral, o Vício, com a figura

\footnotetext{
${ }^{21}$ WEIMANN; BRUSTER. Shakespeare and the Power of Performance: Stage and Page in the Elizabethan Theatre, p. 80. GURR, apud KASTAN. Shakespeare's Playhouses, p. 362 .

${ }^{22}$ WILES. Shakespeare's Clown: Actor and Text in the Elizabethan Playhouse, p. 23. 23 "Carnival needs an authority to antagonize" (PREISS. Clowning and Authorship in Early Modern Theatre, p. 67, tradução minha).

${ }^{24}$ PREISS. Clowning and Authorship in Early Modern Theatre, p. 68.
} 
do herói trágico, Hamlet. ${ }^{25} \mathrm{Na}$ tragédia que leva seu nome, o protagonista assume a função mediadora do clown, como bobo da corte, situandose no limiar entre ficção e plateia para nos fazer alternar perspectivas constantemente, ora desnudando os aspectos trágicos de sua sina, ora expondo o lado cômico de suas circunstâncias e até da própria existência.

Um clown pode aparecer sob os mais diversos rótulos sociais: seja criado, rústico, pedante, trapaceiro ou bobo, ele sempre se sente à vontade para transitar pelos mais variados estratos sociais e despejar seu humor diante de nobres, príncipes, reis e outras autoridades. No terreno da tragédia ou da comédia, ele se mantém em contato direto com o espectador e continua tendo o riso como seu principal objetivo - às vezes ele nos leva ao riso com jigs, espancamentos e trocadilhos sexuais, mas também há ocasiões que seu senso de humor nos torna mais sábios. ${ }^{26}$

Performances cômicas como as de Feste (Noite de Reis), de Touchstone (Como quiserem) e do Bobo de Lear são extensas, ocupando o palco várias vezes no decorrer da trama. Mas há outras, como a do porteiro em Macbeth, a dos coveiros em Hamlet e a do clown com a cesta em Antônio e Cleópatra que incluem somente uma aparição em um momento-chave da peça. Na grande maioria dos casos, no entanto, esses clowns exercem a tarefa de tecer comentários cômicos sobre a ação principal. Uma vez cumprida a missão, eles podem desaparecer sem atrapalhar o desenrolar da história, pois, "são, de fato, mais função do que personagem". ${ }^{27}$ Ao mesmo tempo que nos cativa e nos faz rir, ele é capaz de sumir de uma hora para outra sem causar prejuízo à trama. Quando Lança some em Os dois cavalheiros de Verona, nenhuma personagem nota sua ausência; afinal, no decorrer da história, ele não consegue criar uma relação de afeto e proximidade com ninguém, nem mesmo com seu cão, Azedo. Como afirma Robert Bell, ${ }^{28} \mathrm{em}$ Shakespeare ’s Great Stage Fools, os clowns convencionais compõem interlúdios cômicos; algo que pode ser removido da peça sem danos à sua estrutura. Como o coringa,

\footnotetext{
${ }^{25}$ No primeiro Quarto (1603), o discurso em que Hamlet condena os improvisos dos clowns é estendido para permitir que ele imite seus trejeitos (WILES. Shakespeare's Clown: Actor and Text in the Elizabethan Playhouse, p.viii, 59, 60).

${ }^{26}$ VIDEBAEK. The Stage Clown in Shakespeare's Theatre, p. 3.

27 "They are indeed more function than character". (VIDEBAEK. The Stage Clown in Shakespeare's Theatre, p. 3, tradução minha).

${ }^{28}$ BELL. Shakespeare's Great Stage of Fools, p. 11.
} 
têm efeito temporário e não contam como outra carta qualquer em um jogo de baralho. ${ }^{29}$

\section{O fenômeno do clown}

"From the crown of his head to the sole of his foot, he is all mirth" (Muito barulho por nada, 3.2.9-1130)

Diversos dramaturgos elisabetanos, inclusive Shakespeare, incluíam clowns em suas peças. Mas a obra shakespeariana se distingue das demais pelo modo singular como trata essa figura cômica. Uma análise quantitativa do primeiro Fólio, de 1623, revela a recorrência com que o Bardo fazia menção aos porta-vozes da sua comicidade: o termo clown e suas variantes aparecem com um impressionante total de 99 vezes, enquanto a palavra fool e suas variantes, por sua vez, somam surpreendentes 558 ocorrências. No ranking de ocorrências de termos ligados a folly e clowning, é curioso perceber que nem sempre as comédias ocupam os primeiros lugares; no que diz respeito à palavra fool, é a tragédia do Rei Lear que fica com a primeira colocação, concentrando um total de 104 ocorrências - que garante uma ampla margem de diferença em relação às comédias Noite de Reis, com 66 ocorrências; e Como quiserem, com 45. Com relação ao termo clown, Como quiserem lidera o ranking com 12 ocorrências; na segunda colocação, ficam empatadas peças tão diferentes quanto Titus Andronicus, Noite de Reis e Bem é o que acaba bem, com 11 ocorrências cada; já o terceiro lugar fica com Trabalhos de amor perdidos e Conto de inverno, com um total de 10 ocorrências cada.

Em seu livro The Stage Clown in Shakespeare's Theatre, Bente Videbaek ${ }^{31}$ nos conta que há lugar para pelo menos um clown em praticamente todas as peças shakespearianas. Às vezes, apenas uma ou duas linhas são destinadas à fala do clown; mas em boa parte das peças - sejam elas tragédias, comédias, romances ou peças históricas

\footnotetext{
${ }^{29}$ BELL. Shakespeare's Great Stage of Fools, p. 10.

${ }^{30}$ Formato de paginação refere-se ao ato, cena e linhas do referente texto nas peças.

${ }^{31}$ VIDEBAEK. The Stage Clown in Shakespeare's Theatre, p. 1.
} 
- fica reservado para ele um papel mais proeminente, frequentemente responsável por convidar o leitor ou o espectador a examinar a trama por outro ângulo. Segundo Lucile Charles, ${ }^{32}$ o clown é a figura de quem ouvimos impropérios; é aquele que mantém um vínculo estreito com temas tabus, e cujos trocadilhos nem sempre intencionais provocam um riso cheio de constrangimento. Ele é dono da nossa simpatia e, quase sempre nas vezes em que entra em cena, ele rouba o foco de nossa atenção. A principal característica que distingue o clown é a sua ambivalência ao mesmo tempo que ele é personagem, também não nos esquecemos de que é ator:

Clown-atores elisabetanos sabiam como criar uma dupla persona - Kemp/ Bottom, Armin/ Touchstone, Singer/ Assinico - e, assim, eles eram capazes de falar por si próprios - como Kemp, Armin e Singer - e olhar o público nos olhos. [...] o clown projetava seu ponto de vista sobre o papel que representava. Não havia qualquer tentativa de recriar um mundo 'real' consistente no teatro elisabetano, nem mesmo a suposição de que a tarefa do ator envolveria reexperimentar as emoções da personagem, nem a proposta de que os espectadores fossem voyeurs invisíveis. O clown representava com, e não para, e os espectadores eram construídos como seus iguais. ${ }^{33}$

Em outras palavras, "ele é ele mesmo; [...] e todos sabem que ele é ele mesmo". ${ }^{34}$ Nos palcos da Londres elisabetana e jaimesca, os

${ }^{32}$ CHARLES. The Clown's Function, p. 32.

33 "Elizabethan clown actors knew how to create a double persona - Kemp/ Bottom, Armin/ Touchstone, Singer/ Assinico - and they could therefore speak as themselves Kemp, Armin, Singer - and could look their audience in the eye. [...] the clown would project a point of view about the role which he presented. There was no attempt to recreate a consistent 'real' world in Elizabethan theatre, no assumption that the actor's task involved re-experiencing the emotions of the character, no proposal that the audience were invisible voyeurs. The clown performed with, and not to, an audience constructed as equals" (WILES. Shakespeare's Clown: Actor and Text in the Elizabethan Playhouse, p. 179, tradução minha).

34 "He is himself; [...]; and everybody knows he is himself" (CHARLES. The Clown's Function, p. 33, tradução minha). 
atores cômicos assumiam as mais diferentes identidades - bobos da corte; parasitas; cavalheiros, como o irresistível Sir John Falstaff e o esperto Sir Toby Belch; policiais atrapalhados, como Dull, Dogberry e Elbow; os criados de língua afiada, como Lança, Raio e Grumio; rústicos, como o tecelão Bobina, o carpinteiro Quina, o consertador de foles Sanfona e o funileiro Cristopher Sly; o trapaceiro Autolycus e até criaturas encantadas como o travesso Puck - os grandes atores cômicos da companhia de Shakespeare representavam todos esses papéis sem nunca deixar de ser eles mesmos. ${ }^{35}$ Segundo Richard Preiss ${ }^{36}$ clowns se distinguem das demais personagens do universo shakespeariano por serem quase sempre rústicos ${ }^{37}$ e essencialmente cômicos. Nomes monossilábicos e que nos remetem à concretude da vida quotidiana caem como uma luva para personagens retiradas da vida ordinária, povoada por porteiros, pastores, policiais, bêbados, malandros e espertalhões:

[...] estranhos à vida metropolitana e aos seus modos, mas sábios o bastante para criticá-los; estranhos às nuances da linguagem, mas astutos o bastante para manipulá-la; estranhos à duplicidade do desejo humano e à complexidade das relações sociais, mas inteligentes o bastante para sobreviver a elas; estranhos ao mundo da peça em que se encontram, mas felizes o bastante para comentar esse fato. Se seus nomes são uma visão da vida reduzida à simplicidade atômica, uma enciclopédia de objetos caseiros, partes do corpo, barulhos, instrumentos, comida, é justamente por isso que eles conquistam uma singularidade teimosa, que não deseja ou é incapaz de fazer seu individualismo peculiar se render às forças das pretensões sociais. ${ }^{38}$

${ }^{35}$ CHARLES. The Clown's Function, p. 34. PREISS. Clowning and Authorship in Early Modern Theatre, p. 1.

${ }^{36}$ PREISS. Clowning and Authorship in Early Modern Theatre, p. 2.

${ }^{37}$ Há célebres exceções, como é o caso dos cavalheiros Sir John Falstaff, Sir Andrew Aguecheek e Sir Toby Belch.

${ }^{38}[\ldots]$ "strangers to metropolitan life and its manners, but wise enough to critique them; strangers to the nuances of language, but witty enough to manipulate them; strangers to the duplicity of human desire and the intricacy of social relations, but clever enough to survive them; strangers to the world of the play in which they find themselves, and happy enough to remark on that fact. If their names are a vision of life reduced to atomic 
Há também clowns sem nome - como o rústico que leva a áspide até Cleópatra, o porteiro que abre a porta para Macduff, o coveiro que conversa de igual para igual com o príncipe Hamlet, entre muitos outros. A frequência com que diversos papéis são indicados simplesmente como clown revela os contornos claros que já diferenciavam, à época, esse grande tipo cômico das demais personagens do teatro de Shakespeare: costumam ocupar o papel de clown aqueles que falam em uma prosa intensamente carnal e coloquial, que são hierarquicamente inferiores às personagens do enredo principal, que se mostram com pouca capacidade - ou pouca vontade - para cumprir as ordens mais simples de seus superiores, que apanham por conta de sua estupidez ou impertinência, que nos mostram um talento especial para corromper a linguagem, ${ }^{39}$ subverter os significados das palavras e criar trocadilhos engraçados e que às vezes têm nomes ingleses ao invés de nomes estrangeiros. ${ }^{40}$

Suas funções podem ser as mais diversas, mas a principal é oferecer entretenimento. Como diz Antífolo de Siracusa à Drômio, seu criado cômico: "converso com você e me divirto" (2.1.26). Porém, a oferta desse entretenimento traz riscos para o clown: não são as raras as vezes em que, por ultrapassar os limites do decoro ou da paciência de seu senhor na trama, ele é punido fisicamente. É o que acontece com o pobre Drômio de Siracusa: "nunca vi levar tanto cachação por um porquê de tão pouca razão. Bom, então, muito obrigado. [...] Por tudo o que o senhor me deu, assim, de graça" (2.1.45-47, p. 49). Porém, mesmo depois de castigado, o clown não perde o senso de humor; sua teimosia inesgotável the confere uma resistência incrível, capaz de fazê-lo se erguer novamente depois de suportar os piores constrangimentos e humilhações. ${ }^{41}$

A merry England shakespeariana oferecia um terreno fértil para o florescimento da tradição humorística dos clowns: de um lado os feriados e os festivais populares, com seus rituais bem-humorados de jogos e inversão de gênero e hierarquia; do outro, uma longa tradição teatral

simplicity, an encyclopedia of household objects, body parts, noises, instruments, and foodstuffs, by the same token they each attain a stubborn uniqueness, unwilling or unable to surrender their quirky individualism to the forces of social pretense" (PREISS. Clowning and Authorship in Early Modern Theatre, p. 2, tradução minha).

${ }^{39}$ Em Noite de Reis, Feste se descreve como "corruptor de palavras" de Olívia (3.1.33).

${ }^{40}$ PREISS. Clowning and Authorship in Early Modern Theatre, p. 2.

${ }^{41}$ BELL. Shakespeare's Great Stage of Fools, p. 11, 12. 
e social em que não faltavam tipos cômicos no palco e na sociedade. Sir Thomas More, em particular, tinha tamanho apreço por seu bobo, Henry Patenson, que the deu lugar de destaque, bem no centro do seu retrato de família. ${ }^{42}$ Até os grandes monarcas da era Tudor tinham gosto pelo cômico: Henrique VIII mantinha sempre por perto seu bobo Will Somers; de acordo com Southworth, ${ }^{43} \mathrm{o}$ bufão está presente em várias pinturas da época - em uma delas, é retratado de costas para o rei, em um claro gesto de rejeição; em outra, um retrato da família real de 1545, o bobo de Henrique VIII não está só; no lado oposto do quadro também está Jane, a boba da princesa Maria, que poucos anos depois ascenderia ao trono da Inglaterra.

Ao contrário do que parece sugerir o senso comum, a princípio, o próprio Shakespeare não gozava do mesmo prestígio que Will Kemp, o célebre ator cômico que se juntou à companhia Lord Chamberlain's Men no início da década de 1590. Levaria muitos anos para que Shakespeare conquistasse fama e reputação como Kemp, ator conhecido como herdeiro do talentoso e hilário Dick Tarlton. ${ }^{44}$ Para Bell, ${ }^{45}$ não há dúvidas de que a celebridade do clown, Kemp, ajudou a instigar a curiosidade de Shakespeare pelas possibilidades de explorar o cômico em suas obras. Não por acaso, como já foi mencionado, o dramaturgo sempre criou espaço nas suas peças - independentemente do gênero - para abrigar personagens cômicas, povoando o espaço dramático de suas obras com performances humorísticas de tirar o fôlego. Em A comédia dos erros, uma obra de início de carreira, Shakespeare já mostrava aptidão para aumentar o potencial cômico de suas fontes, dobrando a dose de confusão e diversão ao emparelhar dois criados gêmeos aos dois irmãos também gêmeos do enredo principal. Abrindo mão da plausibilidade da trama, Shakespeare se mostra mais interessado em expandir o potencial cômico da peça. ${ }^{46}$

\footnotetext{
${ }^{42}$ BELL. Shakespeare's Great Stage of Fools, p. 9.

${ }^{43}$ SOUTHWORTH. Fools and Jesters at the English Court, p. 95, 96.

${ }^{44}$ David Kastan (Shakespeare and the Book, p. 14) nos conta que o teatro elisabetanojaimesco era um teatro em que atores, como Richard Burbage e Edward Alleyn eram as grandes celebridades - e não os dramaturgos, como Shakespeare e Marlowe.

${ }^{45}$ BELL. Shakespeare's Great Stage of Fools, p. 9.

${ }^{46}$ BELL. Shakespeare's Great Stage of Fools, p. 11.
} 
Segundo Videbaek ${ }^{47}$ o tamanho de uma companhia teatral elisabetana poderia variar, expandido em momentos de sucesso comercial ou encolhendo durante um surto de peste bubônica. Porém, era praticamente uma regra contar com pelo menos dois ou três clowns no elenco: um deles era o comediante de maior destaque, para quem seriam escritos papéis de peso, como o do cavalheiro Sir John Falstaff ou o do criado, Lança; aos demais caberia representar clowns de menor destaque ou mesmo a função de se dividir entre dois papéis. Para Videbaek, ${ }^{48}$ era bastante improvável que Kemp ou Armin assumissem, em uma única peça, dois papéis distintos, por conta da força com que a imagem desses atores marcava as personagens que interpretavam, podendo suscitar expectativas equivocadas especialmente ao representarem papéis que não deveriam ser cômicos. É o que ocorreu, de fato, em uma encenação de The Famous Victories of Henry the Fifth, pela companhia The Queen's Men. Robert Weimann e Douglas Bruster ${ }^{49}$ nos contam sobre a ocasião em que o célebre Tarlton se viu obrigado a representar, além do cômico Dericke, o papel de juiz, por conta da falta de um ator da companhia. Há registros de que o público morreu de rir quando o príncipe desferiu um soco no juiz justamente porque quem o representava era o cômico Tarlton. Na cena seguinte, Tarlton sobe ao palco novamente - só que dessa vez nas roupas do clown Dericke - e pergunta aos demais sobre o incidente do qual ele mesmo havia participado como juiz. ${ }^{50}$ Seria impossível perder a piada, uma vez que a figura do inconfundível ator nunca era completamente eclipsada pelo papel que ele representava. Embora considerados irrelevantes por alguns críticos e diretores, papéis aparentemente menores - como os coveiros de Hamlet, o porteiro de Macbeth e o rústico com a cesta de Antônio e Cleópatra - podem ter grande importância para a confecção do tecido da trama, sinalizando para o leitor ou espectador que a história está prestes a dar uma guinada.

\footnotetext{
${ }^{47}$ VIDEBAEK. The Stage Clown in Shakespeare's Theatre, p. 1.

${ }^{48}$ VIDEBAEK. The Stage Clown in Shakespeare's Theatre, p. 1.

${ }^{49}$ WEIMANN; BRUSTER. Shakespeare and the Power of Performance: Stage and Page in the Elizabethan Theatre, p. 107.

${ }^{50}$ PREISS. Clowning and Authorship in Early Modern Theatre, p. 75.
} 
Para o crítico Raymond Alden, ${ }^{51}$ o uso de recursos humorísticos pode ser detectado abundantemente na obra shakespeariana; e seu principal porta-voz, o clown, costuma ser inserido nas tramas de quatro modos principais:

- Interlúdios: os interlúdios cômicos não são uma invenção shakespeariana; eram usados nas mystery plays medievais, por exemplo, para satisfazer o gosto popular pela farsa cômica levada a cabo por personagens que representavam indivíduos comuns, das camadas mais baixas da sociedade. No teatro elisabetano, por sua vez, era prática recorrente interromper o desenrolar da trama trágica com um interlúdio cômico, protagonizado por um clown. É o que acontece em Romeu e Julieta, na cena do funeral, quando o embate cômico entre o criado Pedro e os músicos suspende o clima de tristeza que havia invadido a casa dos Capuletos com a morte fingida da jovem (4.5.98-135).

- Subenredo: também era comum inserir personagens cômicas na peça de tempos em tempos, permitindo que reaparecessem no palco em diversas cenas. Essas várias aparições formavam um tema secundário ou até mesmo um subenredo. Em Trabalhos de amor perdidos, o subenredo dos criados e dos pedantes serve para ridicularizar as pretensões intelectuais dos nobres; em A comédia dos erros, as confusões envolvendo os Drômios espelha e realça a trajetória cômica de seus senhores.

- Diálogos cômicos no enredo principal: os clowns, por vezes, emprestavam sua linguagem e seus trejeitos para personagens do enredo sério. É o caso do vilão cômico Ricardo III, cujo humor negro e proximidade com a plateia nos remetem à figura do Vício do teatro das moralidades. Também é o caso de protagonistas como Rosalinda, da comédia Como quiserem, e do herói trágico Hamlet.

${ }^{51}$ The Use of Comic Material in the Tragedy of Shakespeare and his Contemporaries, p. 282-286. 
- Entrelace de um enredo cômico e um trágico: às vezes, os enredos cômico e trágico se entrelaçavam de tal modo que se tornavam praticamente indissociáveis. É o caso de interlúdios cômicos que se desenvolviam ao ponto de transformarem a tragédia em tragicomédia. A ameaça de morte que assombra Medida por medida, por exemplo, convive lado a lado com as tiradas satíricas de Lúcio e Pompeu.

Shakespeare era versátil demais para permitir que identificássemos uma única regra no uso do cômico em suas obras. Todavia, ele sempre criava espaço para a comicidade em suas peças, o que certamente agradava tanto ao seu público quanto ao comediante de sua companhia. Por vezes, as cenas do clown podem parecer gratuitas, e se manter distantes da ação principal, como em Romeu e Julieta; por outro lado, também há casos em que o clown invade de fato, a trama trágica, moldando a maneira como interpretamos o enredo principal, como acontece em Hamlet e Antônio e Cleópatra. ${ }^{52}$

Apesar do clown ser uma figura quase onipresente no universo dramático de Shakespeare, é essencial ter cautela para não o tratar como outra personagem qualquer. Richard Preiss ${ }^{53}$ nos alerta sobre a importância de interpretar o clown à luz da forte tensão entre texto e performance que marcava o teatro elisabetano. Afinal, o papel de clown não era como os demais: sua atuação não se limitava ao que estava assinalado no texto dramático - seus improvisos eram a norma, e não a exceção. É justamente a imprevisibilidade da performance dos clowns que faz emergir aquilo de que muitos críticos contemporâneos preferem se esquecer: o caráter inexoravelmente incompleto e instável do texto teatral, em geral, e o do shakespeariano, em particular.

Ora, o que os clowns faziam era justamente extrapolar as falas que lhes eram designadas nos scripts - uma liberdade criticada pelo príncipe Hamlet:

\footnotetext{
${ }^{52}$ ALDEN. The Use of Comic Material in the Tragedy of Shakespeare and his Contemporaries, p. 291.

${ }^{53}$ PREISS. Clowning and Authorship in Early Modern Theatre, p. 5.
} 
E que aqueles que fazem os papéis de bobos não digam mais do que foi escrito para eles; pois há entre eles os que querem rir a fim de fazer rir também certo tipo de néscios espectadores, conquanto nesse interim algum ponto importante da peça devesse ser valorizado. ${ }^{54}$

Mas os textos teatrais que chegaram até nós não englobam tudo que acontecia em uma performance: são apenas um fragmento do evento teatral, uma idealização, na qual algumas vozes são privilegiadas e ali registradas, enquanto outras, embora presentes nas performances da época, não encontraram espaço nas linhas do texto. Estudar as performances cômicas do palco shakespeariano nos exige reconhecer seu apagamento no texto dramático e explicar as condições que permitiram a marginalização do clown, uma das figuras mais proeminentes do teatro da época. ${ }^{55}$ Ao contrário do que faz a crítica shakespeariana tradicional, é preciso deslocar o foco da palavra escrita e da biografia de seu grande criador, Shakespeare, para se concentrar sobre o clown, a mais incontinente criatura do palco elisabetano-jaimesco.

Porém, o clown não foi a única vítima do triunfo do texto sobre a performance: a plateia, principal aliada do ator cômico da época, também era um colaborador ativo da construção da peça, mas poucos registros de suas contribuições sobreviveram até os tempos de hoje. Longe de se comportarem como meros receptores passivos, os espectadores elisabetanos traduziam na prática o significado ambivalente do termo play e mostravam que a peça, para eles, era muito mais um complexo jogo participativo do que um simples espetáculo para ser assistido ${ }^{56}-$ um jogo nos moldes da definição proposta por Huizinga. ${ }^{57}$

As habilidades de alguns dos mais renomados clowns elisabetanos - os improvisos de Tarlton, os jigs de Kemp e as canções de Armin - dirigem nossa atenção para o momento da performance, para as possibilidades do evento teatral. Em certa medida, como asseguram Weimann e Bruster, ${ }^{58}$ estudar o teatro elisabetano significa se debruçar

\footnotetext{
${ }^{54}$ SHAKESPEARE. Hamlet. 3.2.32-6

${ }_{55}^{5}$ PREISS. Clowning and Authorship in Early Modern Theatre, p. 7.

${ }^{56}$ PREISS. Clowning and Authorship in Early Modern Theatre, p. 7.

${ }^{57}$ HUIZING. A Homo ludens.

${ }^{58}$ WEIMANN; BRUSTER. Shakespeare and the Power of Performance: Stage and Page in the Elizabethan Theatre, p. 79.
} 
sobre uma cultura em que a oralidade e o performático tinham um papel central. A companhia teatral itinerante Leicester's Men, a mais famosa da década de 1570, assim como a Queen's Men, cujo sucesso foi um dos grandes marcos dos anos 1580 e 1590, são ícones de uma tradição teatral calcada na oralidade e no talento de seus clowns. Poucas peças chegaram a ser publicadas e a qualidade dos textos escritos não faz justiça ao que era feito no palco. O célebre Tarlton, que além de ator também era autor e dramaturgo "não queria registrar na escrita, ou não conseguia traduzir para ela, sua atuação como clown". ${ }^{59}$ A prática de publicar e imprimir peças teatrais só se tornou recorrente na segunda metade da década de 1590, quase vinte anos depois do estabelecimento dos primeiros teatros, que pouco a pouco faria esmaecer a tradição itinerante das primeiras companhias. $^{60}$

Mesmo depois da prática de impressão se estabelecer, o clown manteve seu papel transgressor e se consagrou como um agente antitextual, capaz de alargar o fosso entre a estabilidade do livro impresso e a imprevisibilidade do evento teatral. ${ }^{61}$ Além disso, para cumprir sua função disciplinar, evitando que a desordem da plateia colocasse em xeque a realização do espetáculo, o clown se comportava como um jogador, cujo oponente era o público, que mirava no ator cômico sua energia agonística. ${ }^{62}$ Os espectadores prestavam "ajuda necessária para a criação do teatro"; ${ }^{63}$ o clown, por sua vez, era uma espécie de protoautor, à medida que tornava cada apresentação teatral única, dotando-a de aspectos dialógicos e performáticos que transformavam cada espetáculo em um evento singular - bem diferente do registrado no papel impresso. ${ }^{64}$

\footnotetext{
59 "he did not wish to write down, or was unable to pen, the way he clowned" (WEIMANN; BRUSTER. Shakespeare and the Power of Performance: Stage and Page in the Elizabethan Theatre, p. 81, tradução minha).

${ }^{60}$ PREISS. Clowning and Authorship in Early Modern Theatre, p. 8.

${ }^{61}$ PREISS. Clowning and Authorship in Early Modern Theatre, p. 8.

${ }^{62}$ PREISS. Clowning and Authorship in Early Modern Theatre, p. 9.

63 "necessary helpers in the creation of theatre". (WILES. Shakespeare's Clown: Actor and Text in the Elizabethan Playhouse, p. x, tradução minha).

${ }^{64}$ PREISS. Clowning and Authorship in Early Modern Theatre, p. 9.
} 
"O clown é o que há de mais antilivro no teatro", 65,66 a mais criativa e imprevisível criatura do palco elisabetano-jaimesco.

\section{Referências}

ALDEN, Raymond M. The Use of Comic Material in the Tragedy of Shakespeare and his Contemporaries. The Journal of English and Germanic Philology, v.13, n. 2, p. 281-298, 1914.

BELL, Robert. Shakespeare's Great Stage of Fools. New York: PalgraveMacmillan, 2011. DOI: https://doi.org/10.1057/9780230337725.

CHARLES, Lucile Hoerr. The Clown's Function. The Journal of American Folklore, v. 58, n. 227, p. 25-34, 1945. DOI: https://doi. org/10.2307/535333.

DOBSON, Michael; WELLS, Stanley (eds.). The Oxford Companion to Shakespeare. Oxford: Oxford University Press, 2001.

GURR, Andrew. Shakespeare's Playhouses. In: KASTAN, David (ed.). A Companion to Shakespeare. Oxford: Blackwell, 1999, p. 362-376. DOI: https://doi.org/10.1111/b.9780631218784.1999.00023.x.

HUIZINGA, Johan. Homo ludens. O jogo como elemento da cultura. Tradução de João Paulo Monteiro. São Paulo: Editora Perspectiva, 2012.

KASTAN, David. Shakespeare and the Book. Cambridge: Cambridge University Press, 2001.

PREISS, Richard. Clowning and Authorship in Early Modern Theatre. Cambridge University Press, 2015. DOI: https://doi.org/10.1017/ CBO9781139567794.

SHAKESPEARE, William. Tradução de Barbara Heliodora. Teatro completo. Rio de Janeiro: Nova Aguilar, 2009. 3 v.

65 "The clown was the most un-booklike thing about theatre" (PREISS. Clowning and Authorship in Early Modern Theatre, p. 10, tradução minha).

${ }^{66} \mathrm{~A}$ tradicional aversão dos porta-vozes da comicidade à palavra escrita está presente na peça de Thomas Nashe intitulada Summer's Last Will and Testament, em que o famoso bobo de Henrique VIII se declara inimigo da tinta e do papel (WEIMANN; BRUSTER. Shakespeare and the Power of Performance: Stage and Page in the Elizabethan Theatre, p. 102). 
SOUTHWORTH, John. Fools and Jesters at the English Court. Gloucestershire: Sutton Publishing, 1998.

VIDEBAEK, Bente. The Stage Clown in Shakespeare's Theatre. London: Greenwood Press, 1996.

WEIMANN, Robert; BRUSTER, Douglas. Shakespeare and the Power of Performance: Stage and Page in the Elizabethan Theatre. Cambridge: Cambridge University Press, 2009. DOI: https://doi.org/10.1017/ CBO9780511481437.

WILES, David. Shakespeare's Clown: Actor and Text in the Elizabethan Playhouse. Cambridge: Cambridge University Press, 1987. DOI: https:// doi.org/10.1017/CBO9780511553417.

Recebido em: 10 de abril de 2019. Aprovador em: 5 de setembro de 2019. 